\title{
Recurrent malignant solitary fibrous tumor of the scalp: a case report and literature review
}

\author{
Ahmed Rabie ${ }^{1}$, Abdulkarim Hasan ${ }^{2}$, Yasein Mohammed ${ }^{2}$, Ayman Abdelmaksoud $^{3}$, Ali A. Rabaan ${ }^{4}$ \\ 'Department of Pathology, Faculty of Medicine, Al-Azhar University, Damietta Branch, Damietta; \\ 2Department of Pathology, Faculty of Medicine, Al-Azhar University, Cairo; \\ ${ }_{3}^{3}$ Mansoura Dermatology, Venereology and Leprosy Hospital, Mansoura, Egypt; \\ ${ }^{4}$ Molecular Diagnostic Laboratory, Johns Hopkins Aramco Healthcare Dhahran, Dhahran, Saudi Arabia
}

\begin{abstract}
Solitary fibrous tumor (SFT) is a rare type of mesenchymal neoplasm that first was discovered in the pleura but can also affect the peritoneum, lungs, mediastinum, and skin. Cutaneous malignant SFT is an extremely rare tumor that resembles dermatofibrosacoma protuberance (DFSP) histologically and immunohistochemically. Herein, we describe a case of malignant SFT that presented as a recurrent mass on the scalp. The first lesion was totally excised one year before recurrence and was diagnosed as a DFSP based on the histopathology and cluster of differentiation 34 immunostaining positivity. Re-examination of the previously examined specimen was considered. Activator of transcription 6 positivity was also detected in the tissue, confirming the diagnosis of a recurrent malignant SFT rather than DFSP. There was no evidence of recurrence, locoregional, or distant metastases at six months after lesion removal with a safety margin.
\end{abstract}

Key Words: Solitary fibrous tumor; Skin cancer; Immunohistochemistry; STAT6

Received: August 4, 2021 Revised: October 26, 2021 Accepted: October 29, 2021

Corresponding Author: Abdulkarim Hasan, MD, Department of Pathology, Faculty of Medicine, Al-Azhar University, Cairo 11884, Egypt

Tel: +20-224012932, Fax: +20-224012932, E-mail: doctorabdulkarim7@gmail.com

Solitary fibrous tumor (SFT) is a type of fibroblastic mesenchymal tumor that originates in the pleura. Extra-pleural sites have been described, including the head and neck, peritoneum, retroperitoneum, genitourinary system, and pelvis. SFTs have been reported rarely in the skin [1-3]. The majority of SFTs is benign in nature, with a few cases of metastasizing tumors exhibiting a variety of clinical symptoms [2,4]. Malignant SFT is the most aggressive form, with a higher rate of local recurrence and distant metastasis [5]. It is an extremely rare lesion, particularly in the skin, and frequently presents a histopathological challenge, as many skin malignancies exhibit spindle cell proliferation with frequent histological overlap, resulting in a broad histologic differential diagnosis $[3,6,7]$. Immunohistochemistry is a valuable technique for malignant SFT diagnosis since it often reacts to CD34, signal transducer, and activator of transcription 6 (STAT6) markers but not to cytokeratins (CK), smooth muscle actin (SMA), CD31, S100, or CD68 [7,8]. Immunohistochemistry is required for accurate diagnosis of challenging and rare malignant lesions [9]. The present study describes a case of a recurrent malignant SFT on the scalp.

\section{CASE REPORT}

A 51-year-old male patient who was seemingly healthy presented with a recurrent subcutaneous occipital mass one year after excision. The mass was diagnosed as dermatofibrosarcoma protuberance (DFSP) based on histomorphology and CD34-positive immunostaining, with a size of $5 \times 4 \mathrm{~cm}$ and free margins of at least $0.2 \mathrm{~cm}$. The clinical examination of the new lesion revealed an $8 \times 7 \mathrm{~cm}$ subcutaneous mass with overlying skin ulceration, raising the possibility of recurrent DFSP or a neoplastic epithelial lesion consistent with squamous cell carcinoma. The radiological assessment showed no associated lytic or sclerotic bony lesions. For histopathological examination, the lesion was removed surgically with a safety margin. Gross investigation revealed ulcerated skin overlying a well-defined, lobulated, white, and focally 
necrotic mass (Fig. 1). A spindle cell tumor organized in irregular short bundles with staghorn blood vessels was revealed under microscopic analysis. Tumor cells had large, rounded vesicular nuclei and conspicuous micronuclei, with a small to moderate proportion of eosinophilic cytoplasm. Tumor cell nuclei exhibited a moderate degree of pleomorphism and frequent mitosis, approximately seven mitoses per 10 high-power fields (HPFs), with occasional atypical forms and foci of necrosis (Fig. 2). The tumor had invaded the overlying skin. A storiform pattern was not present. There were no dedifferentiated or anaplastic spots. All surgical margins were devoid of tumor cells, with the nearest free margin measuring $0.5 \mathrm{~cm}$ (side and deep margins).

In the first immunohistochemical panel study, CD34 was significantly positive in most tumor cells, but SMA, desmin, S100, pan-CK, and epithelial membrane antigen showed negative re- sults. B-cell lymphoma 2 (BCL2) marker exhibited weak focal staining. Based on the histomorphological and immunohistochemical results, histopathological differential diagnosis was performed, including malignant solitary fibrous tumor, fibrosarcoma on top of dermatofibrosarcoma, and malignant peripheral nerve sheath tumor. Further immunohistochemical investigation of SOX10, STAT6, and Ki67 was considered, where the Ki67 labeling index was 30\%, and STAT6 exhibited a strong diffuse nuclear positivity (Fig. 3), whereas SOX10 was not expressed. Re-cut and re-examined tissue blocks and slides from previous surgery confirmed the same histomorphology, including the lack of storiform pattern. STAT6 immunohistochemical staining of the primary lesion showed diffuse nuclear positivity.

Consequently, the final diagnosis was recurrent malignant SFT (TNM stage T3). Metastatic risk assessment revealed an interme-
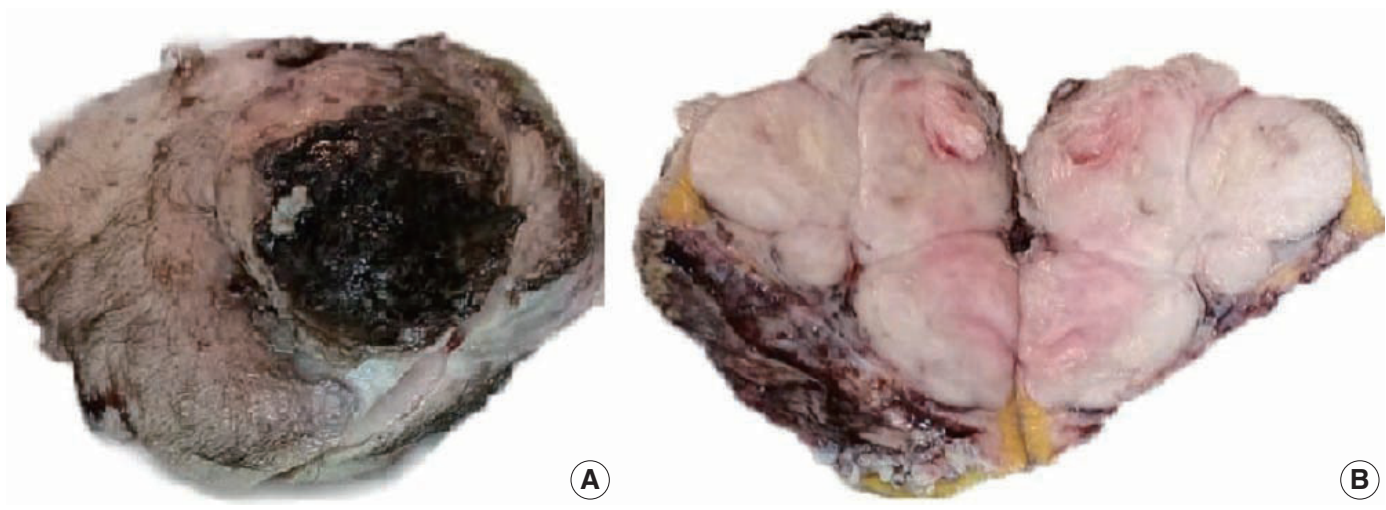

Fig. 1. A gross picture showing ulcerated skin (A) and fairly defined lobulated whitish mass with central focal necrosis (B).
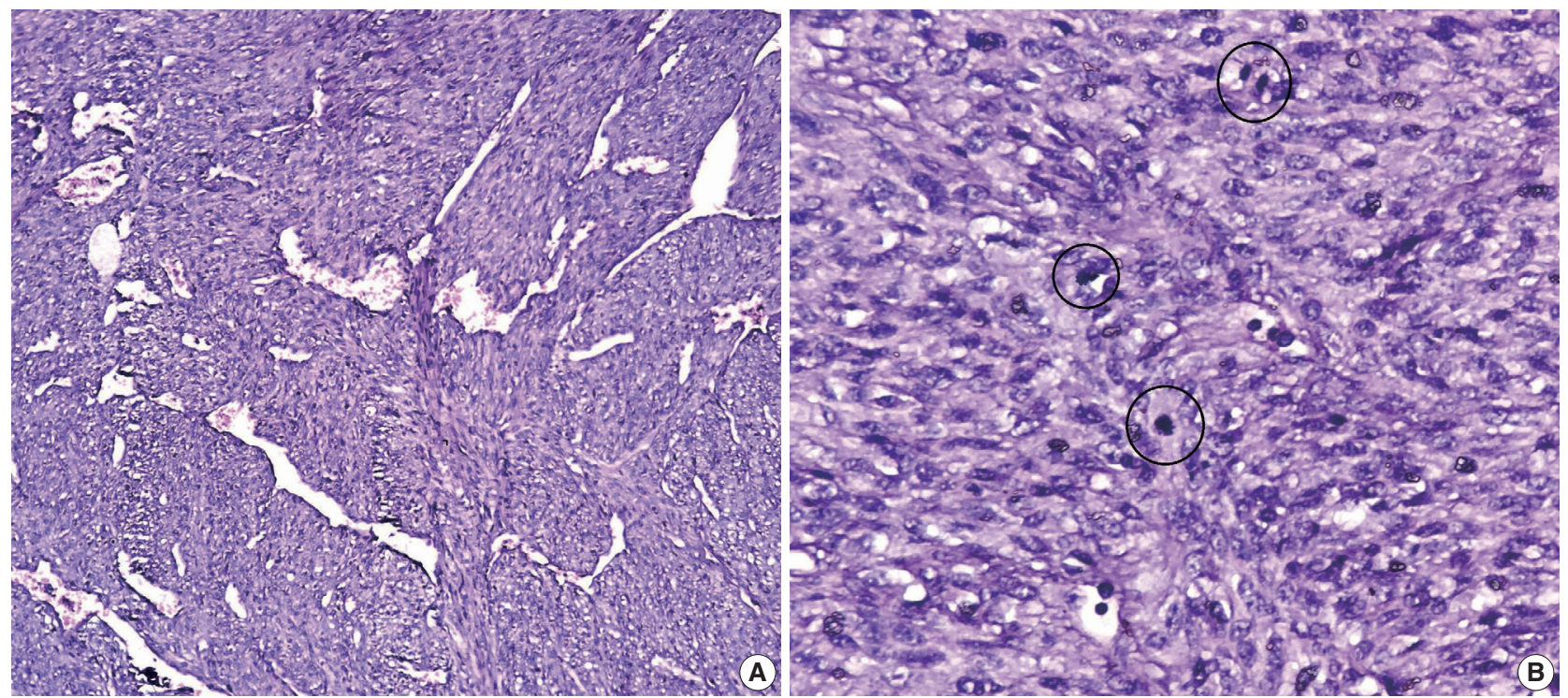

Fig. 2. A histopathology picture showing a cellular spindle cell tumor arranged in irregular short bundles with staghorn blood vessels (A) and mitotic figures (circles) (B). 


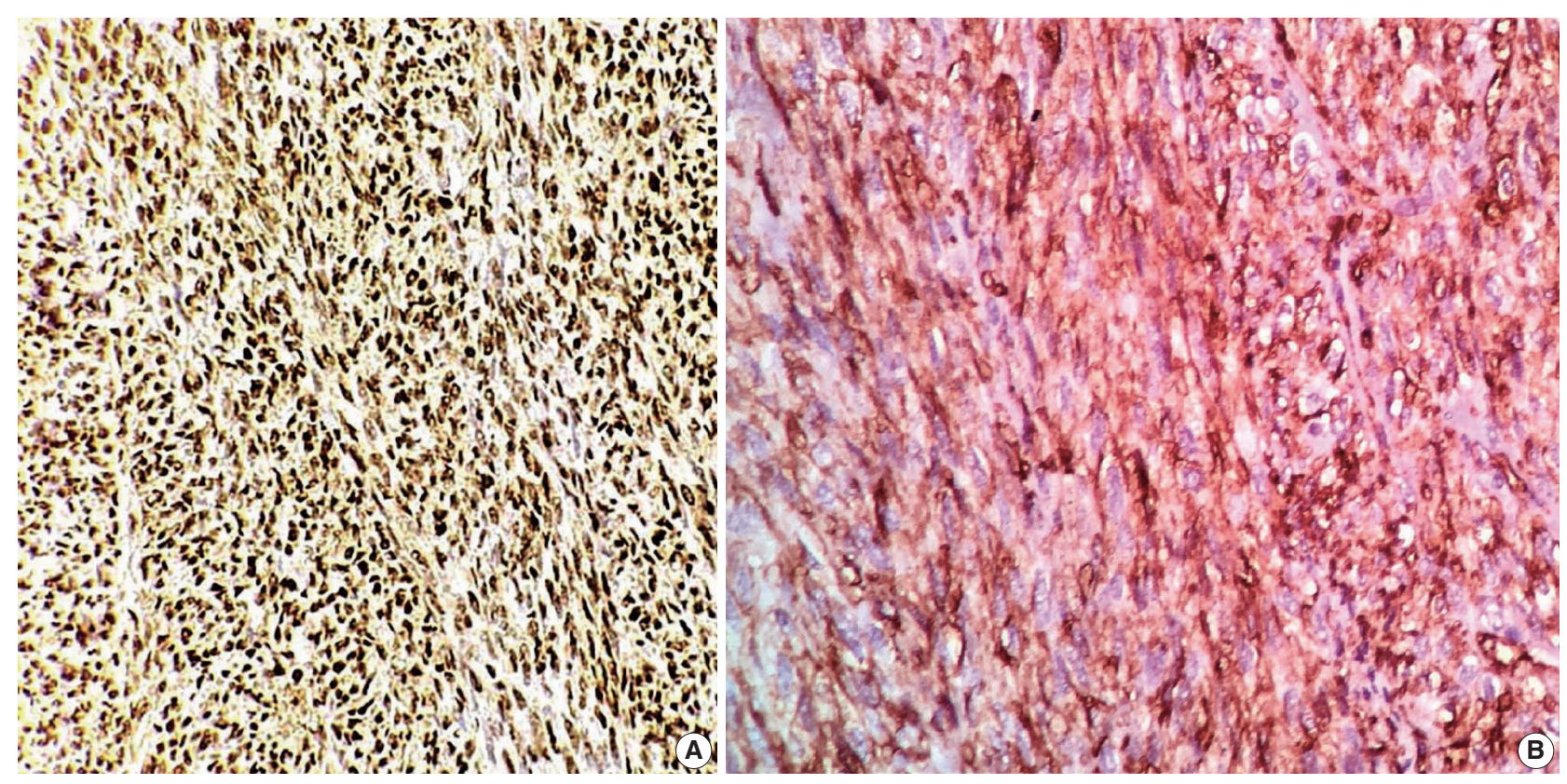

Fig. 3. Immunohistochemical staining. (A) The STAT6 result is positive (diffuse nuclear staining). (B) The CD34 finding is positive (cytoplasmic staining).

diate-risk solitary fibrous tumor. The patient was referred to the oncology department for further evaluation and showed no signs of metastasis at first presentation. Six months later, regular follow-up indicated no evidence of recurrence or distant metastasis.

\section{DISCUSSION}

SFT first was described in 1931 by Klemperer and Rabin as "localized fibrous mesothelioma" [10]. SFT and hemangiopericytoma previously were considered to be distinct entities; however, beginning with the 2013 World Health Organization classification of soft tissue tumors, SFT and hemangiopericytoma are now considered the same neoplasm-except in the central nervous system, where meningeal hemangiopericytoma remains a distinct entity [4]. SFT is frequently found in adults aged 20 to 70 years but has been recorded in children on rare occasions [11]. Although SFTs were initially classified as pleural tumors, they can be found in various tissues, such as the liver, lungs, kidneys, thyroid, neurological system, soft tissue, and skin $[9,12]$. Cutaneous SFT is an extremely rare neoplasm, presenting as a painless, superficial, and well-circumscribed mass that can be confused clinically with lipoma or epidermal cyst [3]. A summary of previously reported cases of scalp SFT and the current one is illustrated in Table 1 [13-24]. Confirming a diagnosis of unusual skin and soft tissue mass lesions, including SFT, is challenging and requires careful sampling of the tumor mass followed by careful pathological examination $[25,26]$. Although fine-needle aspiration cytology is used frequently to diagnose skin and soft tissue masses [27], no definitive cytological findings of SFT have been identified. SFT requires suitable clinical and radiological correlation and immunochemical tests for preoperative diagnosis $[28,29]$. SFT is classified histologically as storiform, hemangiopericytic, herring-bone, diffuse sclerosing, or neural-type palisading. SFT spindle cells proliferate in a "patternless" manner and form dense collagen bundles embedded in the stroma with elaborate vasculature [3]. Malignant SFTs are differentiated from benign SFTs by their high degree of cellularity, size greater than $5 \mathrm{~cm}$, number of mitoses per HPF, presence of immature or pleomorphic tumor cells, and necrosis foci.

A correlation between number of mitoses per HPF and prognosis was observed. At least four mitoses per $10 \mathrm{HPFs}$ are associated with metastasis and recurrence $[4,30]$. There are differential diagnoses for malignant SFT, such as benign SFT, DFSP, nerve sheath tumors, synovial sarcoma, liposarcoma, and leiomyomyosarcomas [31]. Clinico pathological correlation of SFT might not be sufficient to reach a definitive diagnosis. SFTs previously were diagnosed by immunohistochemical expression of various markers, including CD34, CD99, and BCL2; however, these markers carry a poor specificity [7,32]. CD34 is expressed highly in SFTs but also in other tumors that are included in the differential diagnosis of SFTs-namely, DFSP. CD34 is absent in around $5 \%$ to $10 \%$ of SFTs, mostly in dedifferentiated and ma- 
Table 1. A review of existing literature, including case reports and series of scalp SFTs

\begin{tabular}{|c|c|c|c|c|c|c|c|}
\hline Reference & Site & Age (yr) & Sex & $\begin{array}{l}\text { Tumor } \\
\text { behavior }\end{array}$ & $\begin{array}{l}\text { Tumor } \\
\text { size }(\mathrm{cm})\end{array}$ & + ve stains & -ve stains \\
\hline Present case & Scalp (occipital) & 51 & $\mathrm{M}$ & Malignant & $8 \times 7$ & CD34, STAT6, Ki67 (30\%) & $\begin{array}{l}\text { SOX10, actin, desmin, S100, } \\
\text { pan-CK, EMA }\end{array}$ \\
\hline Vasile et al. (2020) [13] & Scalp (meningeal-derived) & 68 & M & Malignant & $6 \times 4$ & $\begin{array}{l}\text { STAT6, BCL2, CD99, } \\
\text { vimentin }\end{array}$ & $\begin{array}{l}\text { CK, CK5/2, keratin } 34 \text { beta E-12, } \\
\text { EMA, P40, S-100, MART-1, } \\
\text { desmin, progesterone receptor }\end{array}$ \\
\hline Mori et al. (2018) [14] & Scalp (mid-occipital) & 37 & $\mathrm{~F}$ & Benign & $2.5 \times 2$ & CD34, STAT6 & S-100, Melan-A, Sox10 \\
\hline \multirow[t]{5}{*}{ Feasel et al. (2018) [15] } & Scalp & 81 & $\mathrm{~F}$ & Benign & 4 & CD34, STAT6 & S-100, cytokeratins \\
\hline & & 55 & $\mathrm{~F}$ & & 1.8 & & \\
\hline & & 64 & $\mathrm{~F}$ & & 2 & & \\
\hline & & 31 & $\mathrm{~F}$ & & 3 & & \\
\hline & & 31 & $\mathrm{~F}$ & & NA & & \\
\hline Kim et al. (2017) [16] & Scalp (left side) & 20 & $\mathrm{~F}$ & $\begin{array}{l}\text { Benign } \\
\text { (myxoid) }\end{array}$ & $4 \times 1.5$ & CD34 & BCL2, SMA, S-100, desmin \\
\hline Shirley et al. (2016) [17] & Scalp (posterior) & 37 & F & Malignant & $6 \times 4.5$ & $\begin{array}{l}\text { FLI-1, BCL2, CD99, } \\
\text { CD34 }\end{array}$ & $\begin{array}{l}\text { CD57, EMA, HMB-45, S100, } \\
\text { CD31 }\end{array}$ \\
\hline Omori et al. (2014) [18] & Scalp (posterior) & 64 & M & Benign & $4.5 \times 2$ & CD34, BCL2 & EMA, SMA, desmin, S-100 \\
\hline Rizk et al. (2013) [19] & Scalp (parietal region) & 2 & M & Benign & NA & CD34 & $\begin{array}{l}\text { SMA, desmin, h-caldesmon, } \\
\text { S-100 }\end{array}$ \\
\hline Tourabi et al. (2008) [20] & Scalp (left occipital) & - & - & Benign & NA & NA & NA \\
\hline Erdag et al. (2007) [21] & Scalp & 58 & M & Benign & NA & CD34, CD99 & Keratin, EMA, desmin, S-100 \\
\hline $\begin{array}{l}\text { Ramdial and Madaree } \\
\text { (2001) [22] }\end{array}$ & Scalp & 2.5 & $\mathrm{~F}$ & $\begin{array}{l}\text { Benign } \\
\text { (aggressiv) }\end{array}$ & 15.5 & CD34 & Desmin, S-100 \\
\hline Cowper et al. (1999) [23] & Scalp & 38 & M & Benign & 4 & CD34, vimentin & $\begin{array}{l}\text { Cytokeratin, EMA, SMA, desmin, } \\
\text { factor XIlla, S-100 }\end{array}$ \\
\hline Okamura et al. (1997) [24] & Scalp (subcutabous) & 37 & $\mathrm{~F}$ & Benign & NA & CD34 & $\begin{array}{l}\text { Markers for smooth muscle, } \\
\text { neural, and epithelial differentiation }\end{array}$ \\
\hline
\end{tabular}

SFT, solitary fibrous tumor; STAT6, signal transducer, and activator of transcription 6; CK, cytokeratin; EMA, epithelial membrane antigen; BCL-2, B-cell lymphoma 2; NA, not available; SMA, smooth muscle actin.

lignant instances [33]. Cancers of the nervous system, melanocytic cells, fat, and smooth muscle can be recognized by their positivity for tumor-specific markers such as $\$ 100$, desmin, and SMA, which are non-reactive with SFT tumor cells [8]. Our case was misdiagnosed previously as DFSP based on histomorphology and $\mathrm{CD} 34$ positivity. However, the absence of a storiform pattern in the tissue and the presence of the STAT6 marker validated our findings on both initial and recent/recurrent specimens. Detection of the NAB2::STAT6 fusion gene in SFTs is a reliable distinction from other spindle cell tumors. NAB2 is a transcriptional repressor of the early growth response transcription factor, and its fusion with STAT6 can convert the repressor into a transcriptional activator, driving neoplastic progression [34]. This finding led to identification of STAT6 immunohistochemical study as a highly sensitive and specific marker for SFTs, whereas DFSP is STAT6-negative [35]. Surgical resection with safety margins is the preferred treatment for both malignant SFTs and DFSP, but chemo-and radiotherapy can be challenging. Adjuvant chemotherapy and radiotherapy are not used widely due to the rarity of SFTs. However, chemotherapy can be beneficial in malignant situations where the tumor appears to be radiation-responsive, implying a more significant chance of reduction in local recurrence $[36,37]$.

While SFT of the scalp is uncommon, malignant SFT is even more uncommon and should be distinguished carefully from other spindle cell tumors of the skin, especially DFSP. To the best of our knowledge, this case is the third report of malignant SFT on the scalp and the first reported case of recurrent SFT at this anatomical site. CD34 immunostaining is insufficient to specify a malignant SFT of the skin. Thus, STAT6 markers should be included in the immunohistochemical panel for differential diagnosis of challenging cases of superficial spindle cell neoplasms.

\section{Ethics Statement}

Ethical committee approval from the Faculty of Medicine, Al-Azhar University board is provided (ID: IRB 00012367-21-03-008). Informed consent was obtained from the patient.

\section{Availability of Data and Material}

All data generated or analyzed during the study are included in this published article (and its supplementary information files).

\section{Code Availability}

Not applicable. 


\section{ORCID}

Ahmed Rabie

Abdulkarim Hasan

Yasein Mohammed

Ayman Abdelmaksoud

Ali A. Rabaan

\section{Author Contributions}

Conceptualization: AR, AH, YM, AA, AAR. Data curation: AR, AH, YM. Formal analysis: AR, AH, AA, AAR. Investigation: AR, AH, YM, AA, AAR. Project administration: AH. Resources: AR, AH, AA, AAR. Software: AR, AH, AA. Supervision: AR, AAR. Validation: AR, AH, YM, AA, AAR. Visualization: AR, AH, YM. Writing-original draft: AH, AA. Writing-review \& editing: AR, AH, YM, AA, AAR. Approval of final manuscript: all authors.

\section{Conflicts of Interest}

The authors declare that they have no potential conflicts of interest.

\section{Funding Statement}

No funding to declare.

\section{References}

1. Hasegawa T, Matsuno Y, Shimoda T, Hasegawa F, Sano T, Hirohashi S. Extrathoracic solitary fibrous tumors: their histological variability and potentially aggressive behavior. Hum Pathol 1999; 30: 1464-73.

2. Zhou Y, Chu X, Yi Y, Tong L, Dai Y. Malignant solitary fibrous tumor in retroperitoneum: a case report and literature review. Medicine (Baltimore) 2017; 96: e6373.

3. Shin K, Kim TW, Lee HJ, et al. A case of malignant solitary fibrous tumor of the skin. Ann Dermatol 2019; 31: 226-8.

4. Fletcher CD, Bridge JA, Lee JC. Extrapleural solitary fibrous tumour. In: Fletcher CD, Bridge JA, Hogendoorn PC, Meertens F, eds. WHO classification of tumours of soft tissue and bone. 4th ed. Lyon: IARC Press, 2013; 80-2.

5. Lococo F, Cesario A, Cardillo G, et al. Malignant solitary fibrous tumors of the pleura: retrospective review of a multicenter series. J Thorac Oncol 2012; 7: 1698-706.

6. Creytens D, Ferdinande L, Van Dorpe J. Histopathologically malignant solitary fibrous tumor of the skin: a report of an unusual case. J Cutan Pathol 2016; 43: 629-31.

7. Ronchi A, La Mantia E, Gigantino V, et al. A rare case of malignant solitary fibrous tumor in prostate with review of the literature. Diagn Pathol 2017; 12: 50.

8. Geramizadeh B, Marzban M, Churg A. Role of immunohistochemistry in the diagnosis of solitary fibrous tumor, a review. Iran J Pathol 2016; 11: 195-203.

9. Kwon JH, Song JS, Jung HW, Lee JS, Cho KJ. Malignant solitary fibrous tumor with heterologous rhabdomyosarcomatous differentiation: a case report. J Pathol Transl Med 2017; 51: 171-5.

10. Klemperer P, Coleman BR. Primary neoplasms of the pleura: a report of five cases. Am J Ind Med 1992; 22: 1-31.

11. Guo W, Xiao HL, Jiang YG, et al. Retrospective analysis for thirtynine patients with solitary fibrous tumor of pleura and review of the literature. World J Surg Oncol 2011; 9: 134.

12. Geramizadeh B, Banani A, Moradi A, Hosseini SM, Foroutan H. Intrapulmonary solitary fibrous tumor with bronchial involvement: a rare case report in a child. J Pediatr Surg 2010; 45: 249-51.
13. Vasile G, Mancuso C, White R, et al. Rare meningeal-derived malignant hemangiopericytoma/solitary fibrous tumor grade II-III presenting as a subcutaneous mass on the scalp. JAAD Case Rep 2020; 6: 861-3.

14. Mori S, Lezcano C, Miraflor AP, Busam KJ, Lee EH. Solitary fibrous tumor presenting on the scalp: a potential diagnostic pitfall. J Cutan Pathol 2018; 45: 557-60.

15. Feasel P, Al-Ibraheemi A, Fritchie K, et al. Superficial solitary fibrous tumor: a series of 26 cases. Am J Surg Pathol 2018; 42: 77885.

16. Kim JH, Kim DC, Lee R, et al. Myxoid solitary fibrous tumor on the scalp. Arch Craniofac Surg 2017; 18: 269-72.

17. Shirley BM, Kang DR, Sakamoto AH. Malignant solitary fibrous tumor of the scalp. J Maxillofac Oral Surg 2016; 15: 245-8.

18. Omori Y, Saeki H, Ito K, et al. Solitary fibrous tumour of the scalp. Clin Exp Dermatol 2014; 39: 539-41.

19. Rizk T, Awada A, Sebaaly A, Hourani R. Solitary fibrous tumor of the scalp in a child. J Neurosurg Pediatr 2013; 11: 79-81.

20. Tourabi K, Moussaoui A, Khaless A, et al. Solitary fibrous tumor of the scalp: a case report. Ann Chir Plast Esthet 2008; 53: 526-30.

21. Erdag G, Qureshi HS, Patterson JW, Wick MR. Solitary fibrous tumors of the skin: a clinicopathologic study of 10 cases and review of the literature. J Cutan Pathol 2007; 34: 844-50.

22. Ramdial PK, Madaree A. Aggressive CD34-positive fibrous scalp lesion of childhood: extrapulmonary solitary fibrous tumor. Pediatr Dev Pathol 2001; 4: 267-75.

23. Cowper SE, Kilpatrick T, Proper S, Morgan MB. Solitary fibrous tumor of the skin. Am J Dermatopathol 1999; 21: 213-9.

24. Okamura JM, Barr RJ, Battifora H. Solitary fibrous tumor of the skin. Am J Dermatopathol 1997; 19: 515-8.

25. Hasan A, Nafie K, Monazea K, Othman A, Salem A, Ismail A. A rare case of recurrent eccrine poroma underlying gluteal abscess. Int J Surg Case Rep 2020; 75: 29-31.

26. Wallace SJ, Teixeira R, Miller NF, Raj M, Sheikh H, Sharma R. Extrapleural superficial solitary fibrous tumor on the posterior shoulder: a case report and review of the literature. Eplasty 2018; 18: e31.

27. Hasan A, Deyab A, Monazea K, et al. Clinico-pathological assessment of surgically removed abdominal wall endometriomas following cesarean section. Ann Med Surg (Lond) 2021; 62: 219-24.

28. Gupta N, Barwad A, Katamuthu K, et al. Solitary fibrous tumour: a diagnostic challenge for the cytopathologist. Cytopathology 2012; 23: 250-5.

29. Galed-Placed I, Lopez-Solache L, Reguera-Arias A. Solitary fibrous tumor of the tongue: cytopathologic fine needle aspiration findings. J Cytol 2019; 36: 186-7.

30. Demicco EG, Wagner MJ, Maki RG, et al. Risk assessment in solitary fibrous tumors: validation and refinement of a risk stratification model. Mod Pathol 2017; 30: 1433-42.

31. Bishop JA, Rekhtman N, Chun J, Wakely PE Jr, Ali SZ. Malignant solitary fibrous tumor: cytopathologic findings and differential diagnosis. Cancer Cytopathol 2010; 118: 83-9.

32. Paner GP, Aron M, Hansel DE, Amin MB. Non-epithelial neoplasms of the prostate. Histopathology 2012; 60: 166-86.

33. Masuda Y, Kurisaki-Arakawa A, Hara K, et al. A case of dedifferentiated solitary fibrous tumor of the thoracic cavity. Int J Clin Exp Pathol 2014; 7: 386-93.

34. Robinson DR, Wu YM, Kalyana-Sundaram S, et al. Identification of recurrent NAB2-STAT6 gene fusions in solitary fibrous tumor by 
integrative sequencing. Nat Genet 2013; 45: 180-5.

35. Doyle LA, Vivero M, Fletcher CD, Mertens F, Hornick JL. Nuclear expression of STAT6 distinguishes solitary fibrous tumor from histologic mimics. Mod Pathol 2014; 27: 390-5.

36. Cardillo G, Lococo F, Carleo F, Martelli M. Solitary fibrous tumors of the pleura. Curr Opin Pulm Med 2012; 18: 339-46.

37. Martin-Broto J, Stacchiotti S, Lopez-Pousa A, et al. Pazopanib for treatment of advanced malignant and dedifferentiated solitary fibrous tumour: a multicentre, single-arm, phase 2 trial. Lancet Oncol 2019; 20: 134-44. 